\title{
A simplified model of converter ideal fundamental wave based on switching function Zheng Weijie
}

China Electric Power Research Institute,Power system department, Haidian District of Beijing, 100192, China.

dianlidianzi_@163.com

Keywords: Switching Function; Converter Model; Transient Simulation

\begin{abstract}
Switching function is a powerful tool for the research and performance optimization of converter, including voltage source converter, current source converter (CSI) and controlled PWM rectifier (CR). The paper proposed converter simplified model based on switching function, theory correctness compared to Matlab calculation results verified the proposed model.
\end{abstract}

\section{Introduction}

With the rapid growth of power electronic and computer control technology, novel equipment such as flexible alternative transmission and flexible direct current transmission based on voltage source converter has been widely used in power system[1-3], in the meantime, distribution power and novel energy also account for a growing proportion, model power system operation stability become more and more dependent on the power electronic devices and the dynamic characteristics of their control systems[4-7].

The power electronic device is essentially a fast periodic action of numeric switching models, with very strong non-linearity, the traditional electromagnetic transient simulation algorithm has some problems in tacking with the development of electromagnetic transient simulation of switching functions[8-10].

Numerical oscillation is one thorny problem in the power electronic simulation[11-14]. In some special cases, switch operation may generate the numerical oscillations in calculating transient process, such as switching action make a sudden change in the voltage drop of inductance at both ends or current flow through a capacitor, which may generate the numerical oscillation, this event once occurs will affect calculation results .

Switching action delay problem is another sticky technical difficulty of switching action in electromagnetic transient simulation[9-13]. Fixed step electromagnetic transient simulation program keep the simulation step constant in the whole process of simulation, however, on the other hand, AC-DC power system common switch, circuit breaker or commutation device thyristor's on-off switching operations are random[14-17]. In other words, when the switching operation occurs between two steps in the electromagnetic transient simulation, the switching simulation process delay problem will be generated if the program does not use any measures, which will damage the simulation precision.

\section{Model Of Single Converter Ideal Fundamental Wave Based On Switching Function}

Single converter is commonly used in the single ended system similar to STATCOM[18-22], direct current capacitor is used for voltage support. Compared to back-to-back converter, a single converter contains only one converter bridge, which do not has the ability to support active power and need to hold capacitor voltage constant.Equation of single converter is shown as formula (1) and (2)[21-24], the formula (1) is in the same form to the one end of back-to-back converters, capacitor voltage balance equation represented by formula (2) only consider capacitance and one end of the active power exchange. 


$$
\begin{aligned}
& L_{1} \frac{d i_{1 a}}{d t}+R_{1} i_{1 a}=u_{1 a}-\frac{u_{1 r a}}{2} v_{d c} \\
& L_{1} \frac{d i_{1 b}}{d t}+R_{1} i_{1 b}=u_{1 b}-\frac{u_{1 r b}}{2} v_{d c} \\
& L_{1} \frac{d i_{1 c}}{d t}+R_{1} i_{1 c}=u_{1 c}-\frac{u_{1 r c}}{2} v_{d c} \\
& C \frac{d u_{d c}}{d t}=\frac{1}{2}\left(u_{1 r a} i_{1 a}+u_{1 r b} i_{1 b}+u_{1 r c} i_{1 c}\right)
\end{aligned}
$$

In order to maintain the flexibility of the model, the DC side capacitor of the converter is not included in the model. Converter bridge model is not included in the DC part, only reserved a dc node interface. Compared with a single inverter, the branch equation of the AC side is the same as that of the formula (1); the DC side does not exist corresponding to the capacitance dynamic equation of (2), and the relationship between the DC current and the three-phase alternating current [21-24]is shown in the formula (3):

$$
i_{d c}=\frac{1}{2}\left(u_{1 r a} i_{1 a}+u_{1 r b} i_{1 b}+u_{1 r c} i_{1 c}\right)
$$

Converter bridge on the AC side is connected to the AC network, DC side is connected with a DC network, in the program in order to avoid the iteration between the AC-DC network which might reduce the speed of the calculation, the AC DC network are solved independently: DC side needs to predict DC node current of DC bus converter bridge, which will be injected into DC network; AC side need to predict the DC side capacitor voltage, by the way of injecting current and shunt admittance into the communication network.

\section{Electromagnetic transient simulation}

Converter and converter bridge is a typical power electronic converter, which is an important component of new energy and new type of power electronic equipment. This chapter puts forward converter and variable flow bridge ideal fundamental simplified model can be applied to high-speed self turn off devices composed of power electronic equipment electromagnetic transient modeling, so as to solve the problems of this kind of power electronic equipment with electromagnetic transient model of calculation speed is slow. Section of the wind turbine model as an example, introduces the application of simplified model of converter ideal fundamental in electromagnetic transient simulation of power electronic equipment.

Figure 1 is a double fed wind turbine electromagnetic transient simulation example, including the double fed motor, converter and wind turbine (Implementation in the user defined UD), the wind machine is connected to the infinite bus.

"Inducti onmachine-224

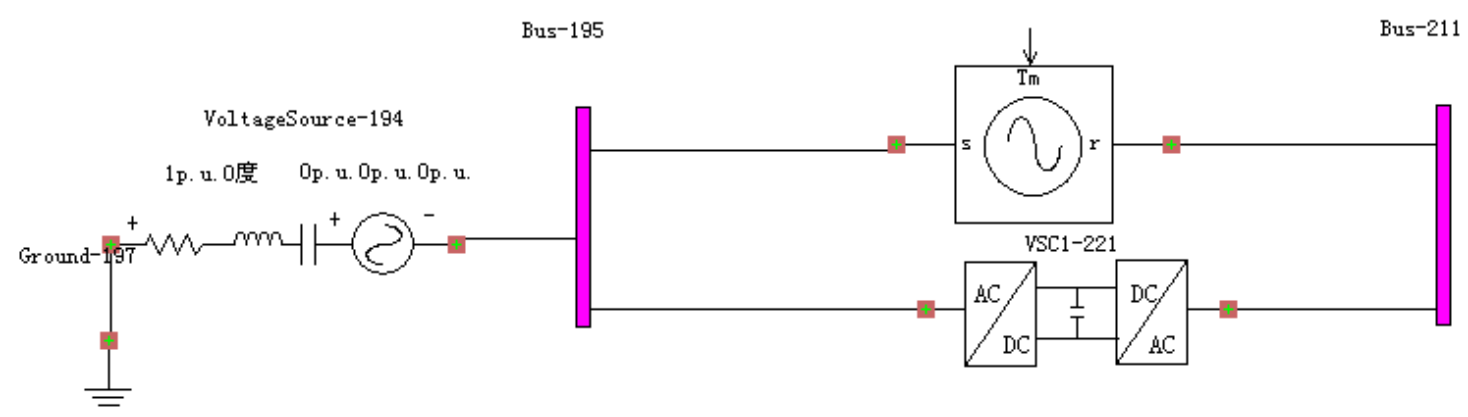

Figure 1 Example of double fed wind turbine

The rotor side converter has double closed loop control structure, whose the outer loop is the power control loop, and the inner loop is the current control loop. By measuring the stator and rotor 
voltage and current, the stator active power Ps and stator reactive power Qs can be calculated and compared to the given values of stator active Pref and reactive power Qref.

Through PI regulation generated given value iqr_ref and idr_ref of rotor dq current, after comparing to actually feedback of iqr and idr , they will be sent into PI regulator, so as to obtain the control voltage of the $\mathrm{d}$ and $\mathrm{q}$ axis. After reverse Park transform can obtain control voltage component in three-phase coordinates. For wind turbine model of grid side converter, active power control objectives is in order to maintain DC voltage constant; reactive power control objectives is for absorption of specified reactive power (for reactive power step response test).

Simulation is taken following, first verify that the effectiveness of the control loop, observing whether the given reference values of order step response meets the controller design requirements; and then test wind speed step response, observing whether the wind machine can tracking maximum wind power.

\section{Electromagnetic transient simulation for step response}

Step response test

First, the step test of DC side voltage is carried out, and the DC side voltage reference value from $1000 \mathrm{~V}$ step to $1050 \mathrm{~V}$ in time $5 \mathrm{~s}$, the simulation curve is as follows figure.1(a). The reactive power step test of the grid side converter is carried out, and the reactive power reference value from the 0 Var step to 1000Var in the 5S, and the simulation curve is as follows figure.2(b):

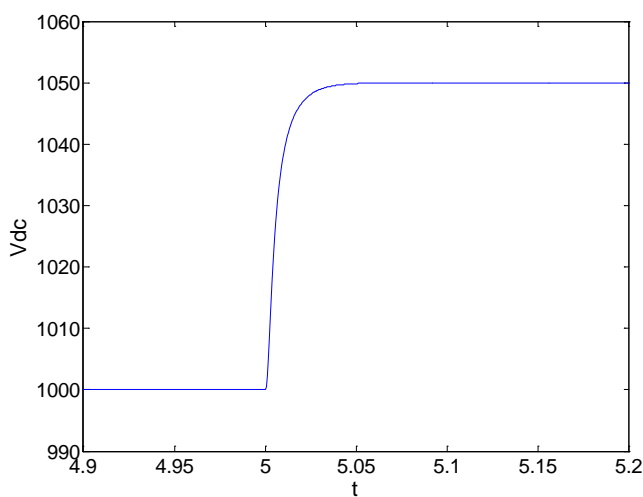

(a)DC voltage step response curve

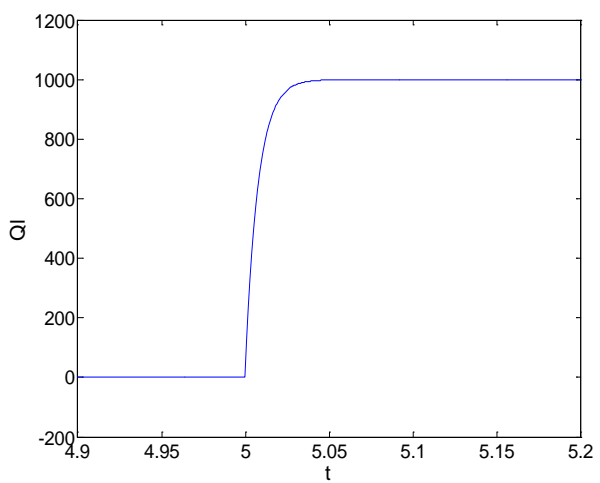

(b) Step response curve in grid side

Figure.2 Step response curves

The reactive power step test is carried out on the stator side of the motor, and the reactive power reference value of the reactive power is stepped from 0Var to -1000Var in the time $5 \mathrm{~s}$, and the simulation curve is as follows in figure 3(a): The active power step test is carried out on the stator side of the motor, and the active power reference value of the $5 \mathrm{~S}$ is stepped from $-4500 \mathrm{~W}$ to $-4800 \mathrm{~W}$, and the simulation curve is as follows n figure 3(b)
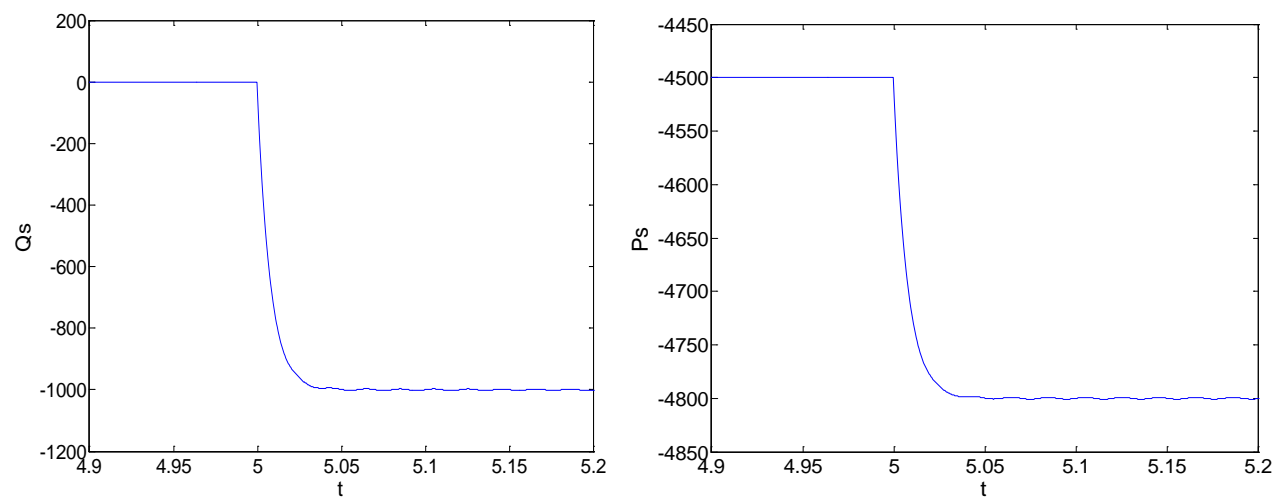

(a)Stator side reactive power step response curve (b)Step response curve of stator side active power Figure.3 Step response curves 
From the simulation tests of the above four control loops, it can be seen that the step response of the reference value meets the requirement of the controller design.

maximum wind energy tracking

Set the wind order step changes in $5 \mathrm{~s}$, wind speed stepped from $6.5 \mathrm{~m} / \mathrm{s}$ to $8.5 \mathrm{~m} / \mathrm{s}$, doubly fed motor stator current curves, rotor current curve of phase A, turn slip curve, the stator power tracking reference value curve, wind turbines use coefficient $\mathrm{Cp}$ curve and wind machine output power curve as shown below:

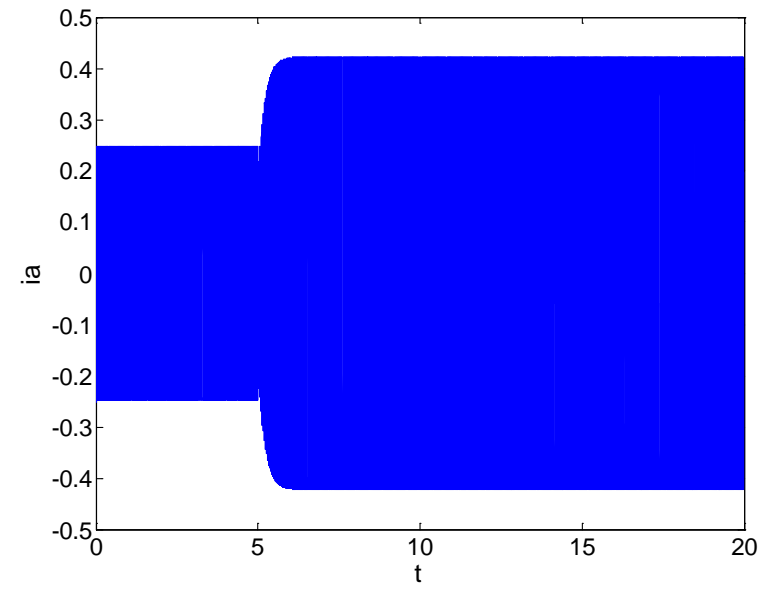

(a)Doubly fed motor stator current curve

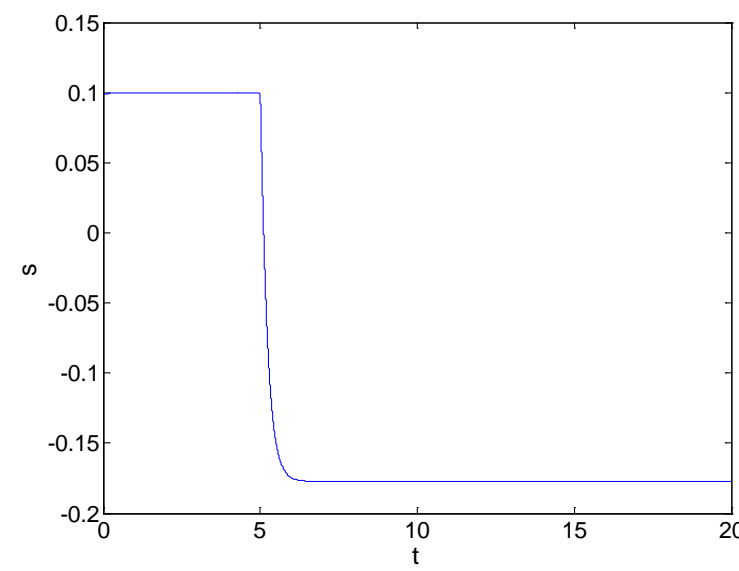

(c)Double fed motor slip curve

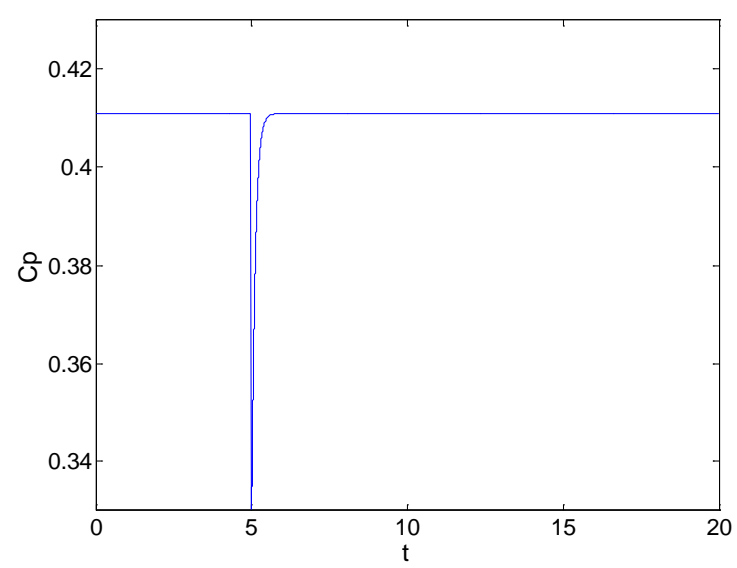

(e)Wind energy utilization coefficient Cp curve

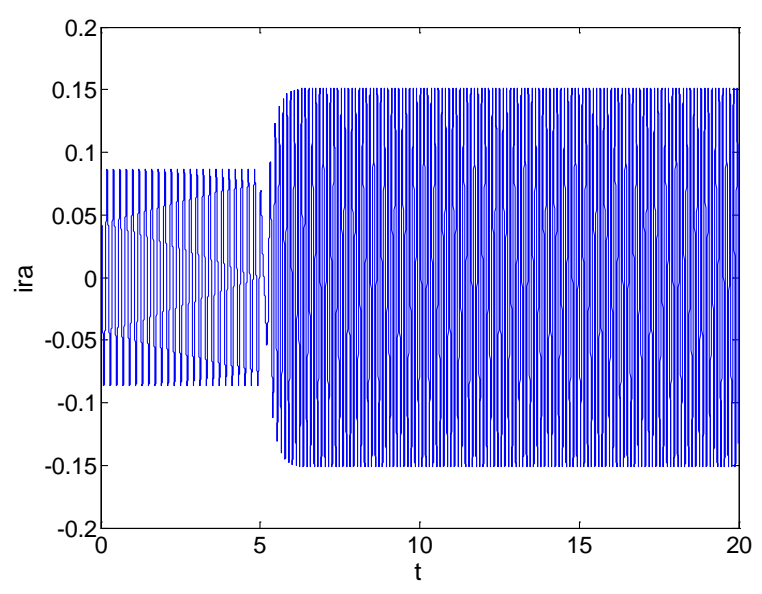

(b)Doubly fed generator rotor current curve

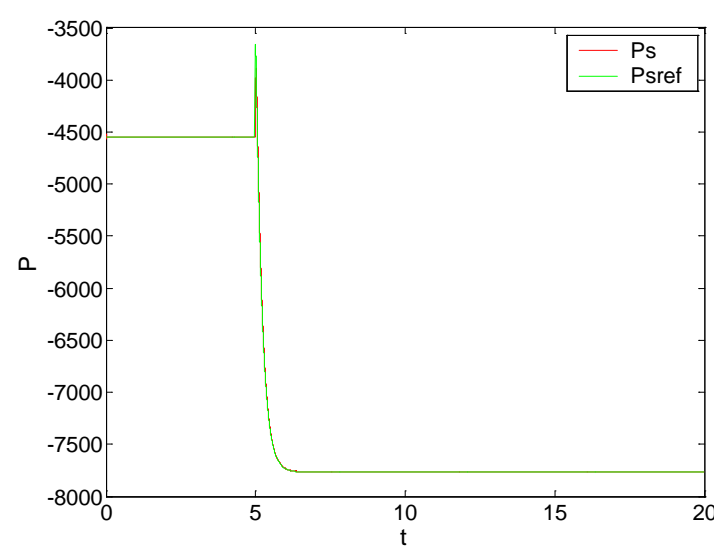

(d)The variation curve of the reference value

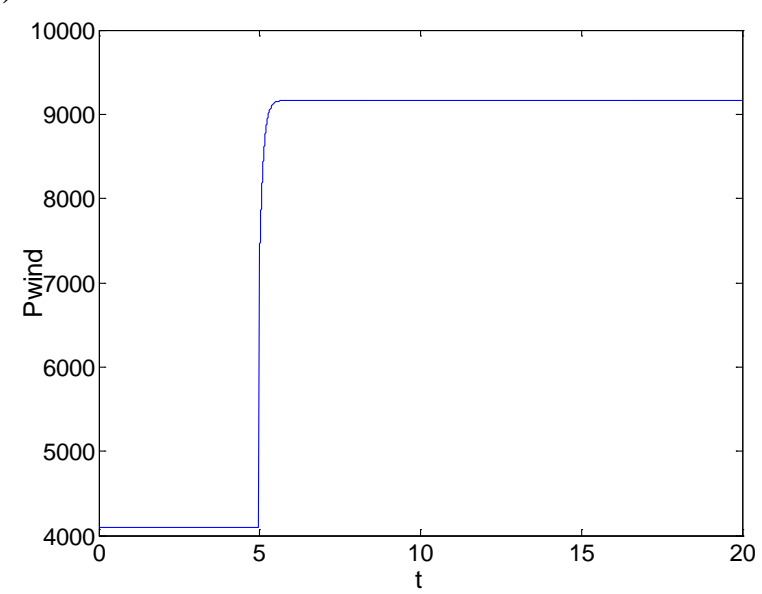

(f) Output power curve of wind turbine

Fig.4. The experimental results

Combined with the above analysis, in the moment of wind speed change, the motor speed can not change suddenly, which lead to Cp decreasing, Psref will decrease deduced from the maximum wind energy tracking formula. The utilization coefficient of the wind is decreased, while, as the 
wind speed increases, the mechanical torque is greater than the electromagnetic torque, which accelerat the unit. it will reach a new steady state after about $1 \mathrm{~s}, \mathrm{Cp}$ is still the maximum value. Seen from the above results, the control strategy achieves the goal of maximum wind energy tracking, which can ensure the stable operation of the unit.

\section{Conclusion}

Based on the analysis of the mechanical theory as the foundation, designed the soccer robot pick the ball institutions optimal design process, found aim function, select design variables and the corresponding optimization algorithm to optimize a complete set of institutions. At last through the test to get the final performance parameters of the institution. Experiments show that the system has higher accuracy and stability, the new optimize pick the ball have design basic requirements, and achieved good ideal control effect.

\section{References}

[1] ZHENG Chao, ZHOU Xiao-xin, LI Ruo-mei. Modeling and analysis for VSC-HVDC using the switching function[J]. Automation of Electric Power Systems, 2005,29(8): 32-35.

[2] LI Xun, YANG Yin-fu, CHEN Jian. Switching function mathematical model of UPFC based on SPWM control[J]. Automation of Electric Power Systems, 2003, 27(9):37-40.

[3] ZHAN Hou-jian1, 2, WU Jie-kang2, KANG Hai-bing3, Modeling and simulation for STATCOM using switching function[J], Power System Protection and Control, Vol.38 No.10, May 16, 2010。

[4] Salazar L, Joos G. PSPICE Simulation of Three-Phase Inverters by Means of Switching Functions[J]. IEEE Trans on Power Electronics,1994, 9(1): 35-42.

[5] Wiechmann E P, Ziogas P D, Stefanovic V R. Generalized Functional Model for Three Phase PWM Inverter/rectifier Converters[A]. In: IEEE IAS’ 86[C].1986. 984-993.

[6] FENG Yu, DONG Hai-bo, TANG Yi. Study of TCSC zero-crossing point characteristics of capacitor voltage based on switch function model[J]. Relay, 2004, 32(17):6-10.

[7] Zheng Weijie, Zhou Xiaoxin. Equivalent electro-magnetic transient model based on dynamic reluctance for magnetically controlled shunt reactor[J]. Proceedings of the CSEE(in Chinese), 2011, 31 (19) : 1-7.

[8] WU Xiao-mei1, XU Xin2, NIE Yi-xiong1, New simulation model of three-phase voltage source inverter based on switching functions[J], Power System Protection and Control, Vol.37 No.11, June 1, 2009

[9] Lee G M and Lee D C .Implementation of Natur ally Sampled Space Vector Modulation Elimination Microprocessors[ C] .Tsinghua, IPEMC' 2000:803 807 .

[10]ZHENG Weijie, ZHOU Xiaoxin, Dynamic Adaptive Inverse Control Algorithm Magnetically Controlled Shunt Reactor Based on Time Varying System Parameters Tracing[J]. Proceedings of the CSEE(in Chinese), 2011, 31（19）: 1-7

[11]Lee B K, Ehsani M. A Simplified Functional Simulation Model for Three-Phase Voltage-Source Inverter Using Switching Function Concept[J]. IEEE Trans on Industrial Electronics, 2001, 48(2): 309-321.

[12]CHEN Hui , YANG Xi-jun , LEI Huai-gang, GONG You-min, Synthesized PWM Inverter Technique Based on Switching Functions[J], Power Electronics, Vo 1.36, No .4 August , 2002 
[13]ZHENG Weijie,Dynamic Difference Correction Tracing Control Algorithm for Bulk Capacity Nonlinear Elements of Power Systems[J],Proceedings of the CSEE,2014.5.5, Vol.34 No.13,:2172-2177. Vol.34 No.19 Jul.5, 2014.

[14]Byoung- Kuk Lee, Ehsami, M. A simplified functional simulation model for three- phase voltage- source inverter using switching function concept[ J] . IEEE Trans. Industrial Eletronics,2001, 48( 2) : 309- 321.

[15]Rasic A, Krebs U, Leu $\mathrm{H}$, et al. Optimization of the modular multilevel converters performance using the second harmonic of the module current[C]//13th European Conference on Power Electronics and Applications. Barcelona, Spain: IEEE, 2009: 1-10.

[16]ZHENG Weijie,Transient Control Algorithm and Strategy of Controllable Shunt Reactors Individual Phase Suppressing Overvoltage and Secondary Arc Current[J],Proceedings of the CSEE,2014.7.5, Vol.34 No.19,PP:3187-3193

[17]Glinka M. Prototype of multiphase modular multilevel converter with $2 \mathrm{MW}$ power rating and 17-leveloutput-voltage[C]//Power Electronics Specialists Conference . Aachen, Germany : IEEE, 2004: 2572-2576.

[18]Lesnicar A , Marquardt R . An innovative modular multilevel converter topology suitable for a wide power range[C]//IEEE Power Tech Conference Proceedings. Bologna Italy: IEEE, 2003: 6 .

[19]Zheng Wei-jie, Zhou Xiaoxin, Adaptive Tracking Algorithm for Magnetically Controlled Shunt Reactor Control, 2010 International Conference on Power System Technology[C], on October, 2010, in Hangzhou, China.pp:A-99 (EI Index).

[20] Antonopoulos A, Angquist L, Nee H P. On dynamics and voltage control of the modular multilevel converter [C]//European Power Electronics and Applications Conference. Barcelona Spain: IEEE, 2009: 1-10.

[21] Richard Gagnon, et al. 《Modeling and real-time simulation of a doubly- fed induction generator driven by a wind turbine》. International Conference on Power Systems Transients (IPST’05)

[22]Gao Jingde et al.the analysis of AC motor and its system" (Second Edition)[M], Press of Tsinghua University.

[23]Zhang Chongwei et al."PWM rectifier and its control" [M],mechanical industry press.

[24]Huang Jun, power electronic converter technology[M], mechanical industry press. 